\title{
The public earnings premium in a mineral rich economy: new piece in the puzzle
}

\author{
Usamah F. Alfarhan ${ }^{*}$ \\ a Department of Economics and Finance, Sultan Qaboos University \\ *Corresponding author's e-mail: ualfarhan@squ.edu.om
}

\begin{abstract}
H I G H L I G H T S:
1. This is the first paper to explain sector selection and the public earnings premium in Saudi Arabia.

2. In the light of the lack of published individual level data, this paper uses a cross-sectional dataset primarily collected in 2013 to conduct the analysis.

3. The public earnings premium is not due to overpayment, rather due to favorable human capital endowments of Saudis, who self-select into public sector jobs.

4. Actual experience, economic sector and worker's self-selection explains most of the observed public earnings premium.
\end{abstract}

\begin{tabular}{ll} 
Article History & ABSTRACT \\
\hline $\begin{array}{l}\text { Received: } 12-11-2014 \\
\text { Revised Received: 06-12-2014 }\end{array}$ & $\begin{array}{l}\text { This paper addresses the determination of sector earnings and the public earnings premium } \\
\text { in Saudi Arabia. It uses a primary cross section of individuals collected in 2013, and employs } \\
\text { Accepted:25-12-2014 }\end{array}$ \\
$\begin{array}{l}\text { the Oaxaca-Blinder decomposition methodology to show whether the observed sectoral } \\
\text { earnings' differential is explained by differences in workers' characteristics or by a favorable } \\
\text { public wage structure. While controlling for selection, the paper shows that public workers } \\
\text { are better endowed rather than overpaid by a wealthy state. This finding suggests that, }\end{array}$ \\
$\begin{array}{l}\text { Keywords: } \\
\text { Earnings' differentials; }\end{array}$ & $\begin{array}{l}\text { contrary to the general belief, the determination of public earnings does not contradict active } \\
\text { Public/private sector earnings; }\end{array}$ \\
labor market policies designed to encourage private sector employment of locals.
\end{tabular}
Selection.

JEL Classification:

$\mathrm{J} 31 ; \mathrm{J} 45$.

DOI: http://dx.doi.org/10.18533/jefs.v3i01.100

(C) 2015 The Authors. This is an open access article under the terms of the Creative Commons Attribution License 4.0, which allows use, distribution and reproduction in any medium, provided the original work is properly cited.

\subsection{Introduction}

Saudi Arabia is one of the largest economies in the Middle East and North Africa region with a gross domestic product of nearly $\$ 530$ billion in 2012 constant prices in 2013 . Around $45 \%$ of Saudi Arabia's output comes from crude oil, as it produced over 9.7 million barrels per day in 2012 (OPEC, 2013). As such, following Russia, it is the second largest producer of crude oil in the world.

The Saudi labor market on the other hand is the largest regionally and is characterized by several key features, in many cases undesired, that have been underexplored in the literature. For instance, according to the Manpower Research Bulletin published by the Central Department of Statistics and Information (CDSI, 2013), Saudi Arabia enjoys a relatively young labor force, as over $60 \%$ is younger than 37 years. Yet, more than $30 \%$ of this young labor force is unemployed. Moreover, there is a considerable wage differential between Saudi's and Non-Saudi's across economic sectors, suggesting the presence of wage discrimination against foreign labor. Also according to the CDSI, 
the female labor force participation rate is among the lowest globally ${ }^{1}$, and women face various barriers to entering many occupations. Furthermore, there is a clear concentration of locals in the public sector, whereas the private sector is dominated by expatriates. Accordingly, this paper focuses on the persistent public earnings premium that is believed to contribute to such concentration, thereby offsetting the government's efforts to increase employment of Saudis in the private sector. Despite the policy significance of this concern, the nature and causes of the public earnings premium have not been explored to this point.

Several government policies are implemented to encourage and increase employment of locals in the private sector. Among such measures is the Hafiz program, literally meaning incentive, by virtue of which unemployed, active jobseekers are allowed SAR2000 (Saudi Arabia follows a fixed exchange rate regime, where USD1 = SAR3.75) monthly for one year. Another policy is the reengineered Saudization program Nitaqat, meaning scopes, with firmsize and employment sector quotas designed to encourage private firms to hire locals, and where non-compliant firms are sanctioned, Ramady (2013). Moreover, the government enforces a SAR3000 minimum wage for Saudis in the public sector. This minimum wage feeds into the Nitaqat program, such that Saudi private sector employees who are not paid accordingly do not fully count in the mandated quota.

In the light of the aforementioned policies, the observed real hourly public sector earnings premium of USD2.68 gains particular relevance, given that pay differentials could be a significant determinant of sector choice, Bedi (1998). It is a general perception that due to reliance on oil revenues, the Saudi government faces relatively less fiscal constraint. In addition, public sector wage determination is not affected by the motive of profit maximization. Therefore, the government can afford to pay and maintain a public wage premium. Since the public sector is dominated by locals however, such a premium leads to an increase in the reservation wage of Saudis who are not working for the state (IMF, 2013, p. 15), which in turn induces profit maximizing private firms to hire the more affordable foreign workers, incorporating the Nitaqat sanctions as a cost.

Therefore, in the case of Saudi Arabia, if identical workers earn more in the public sector as compared with the private sector, this rent can be interpreted as contradicting to active labor market policies. Otherwise, if the premium is due to higher endowments in the public sector, the distribution of Saudi workers between the public and private sectors is more a question of selection and labor supply, as well as firms' labor demand decisions, which have to be addressed accordingly.

To the best of my knowledge, this paper is the first to explain the public earnings premium in Saudi Arabia. This gap in the literature is due to the lack of a dataset with information on individual workers: their employment and their demographic and productivity-related characteristics. This information is necessary to explain their respective earnings and labor supply decisions. Hence, this paper contributes to the literature by filling this gap, and by examining whether the drivers of that public earnings premium contradicts active labor market policies, using a new dataset collected for these purposes.

The literature on public-private pay differentials is quite sizable. Yet, none is found to address the case of Saudi Arabia or any other regional labor market with comparable features. As stated earlier, the main reason for this is rather simple: there are no data. Lausev (2014) surveys the literature on the topic during the previous two decades. She finds that most literature on transitioning economies reports a public earnings penalty, whereas in developed market economies this public pay premium is either zero or positive. Hyder and Reilly (2005) and Aslam and Kingdon (2009) show that the public sector wage premium in Pakistan is mainly explained by differences in worker characteristics. Similar results are found by Kannellopoulos (1997) and Papapetrou (2006) on Greece, Christofides and Pashardes (2002) in the case of Cyprus, and Akhmedjonov and Izgi (2012) on Turkey. Tansel (2005) shows that schooling partially explains the public wage differential. Similarly, education is found to contribute positively to the public premia in each of Djibouti and Uganda as reported by Caserol and Seshan (2006) and Okurut and Ssewanyana (2007), respectively. The evidence found in developing countries, interestingly, confirms the results reported by Jürges (2002) on Germany, Meurs and Edon (2007) on France, Heitmueller (2006) on Scotland, Chatterji, Mumford and Smith (2011) as well as Mumford and Chatterji (2012) on Britain. Likewise, Lassibille (1998) shows that endowments are more important than differences in the returns in accounting for wage differentials between the public and private sectors in Spain. Particularly education and experience explain the majority of the gap. Démurger, Li and Yang (2012) as well as Clément (2013) show those endowments play a growing and important role in each of China and Vietnam.

It has also been emphasized that sector earnings differentials change in size and direction within different segments of the earnings distribution. Mainly, studies find that the public sector premium is higher in the lower tail of the wage distribution. This result is confirmed by Mueller (1998), Rosholm and Nielsen (2001), Panizza and Zhen-Wei (2005), Birch (2006), Lucifora and Meurs (2006) and Giordano (2010). On the other hand, Siminski (2013) finds no evidence

${ }^{1}$ Also see http://wdi.worldbank.org/table/2.2. 
on that the premium varies with the skill. He suggests that the compressed wage profile of the public sector induces the best workers to join the public sector in low-wage occupations, and vise versa in high-wage occupations. Hence, at least with Australian data, low-skill public sector workers may actually not be overpaid.

The remainder of this paper is organized into section 2 which describes the data, section 3 that lays out the implemented methodology and section 4 that summarizes the empirical results. Section 5 concludes.

\subsection{Data and methodology}

This paper uses a new dataset, collected by means of chain-referral sampling over social networks ${ }^{2}$. Saudi Arabia, as well as most other countries in the region, lacks the necessary institutional environment within which individuallevel socio-economic panels (e.g. the Panel Study of Income Dynamics in the U.S. or the German Socio-Economic Panel) are collected and published. As a result, data of this kind is unavailable. Moreover, variables on the Saudi work force such as age groups, educational attainment and sector of employment that are published in statistical bulletins and data outlets, are inaccessible in their disaggregated format.

Due to the uniquely conservative Saudi traditional atmosphere, the accessibility of households, particularly female members, either personally or over the phone is very limited. Nonetheless, several government institutions such as the CDSI and the Ministry of Labor do publish some aggregated data on a number of important variables used in this paper. In turn, these data are used to provide some validity check, given that chain-referral sampling is often associated with potential biases of unknown magnitudes and directions. It turns out, as this section show that the sample means of the survey data are quite close to their officially published equivalents.

The dataset is a socio-economic cross-section in 2013 , where a total of $584^{3}$ locals provided information on their age, gender, marital status and number of children, education, actual experience, job training and tenure, employment type and status, occupational position, industry and sector of employment and the size of employer. Also, respondents provided information on their total received monthly earnings including all cash allowances, contracted weekly working days and daily working hours.

The sample underlying decompositions in this paper however includes only Saudi men between 18-64 years of age, who have completed their education and work in full-time occupations. Military, police and civil defense personnel are taken out because they are not considered within the civil labor force. I also exclude self-employed individuals whose earnings are mainly entrepreneurial and workers in the agricultural sector whose earnings are greatly influenced by seasonality, as well as individuals that fall within the top and bottom $2 \%$ of the earnings distribution in order to neutralize the effect of outliers.

Furthermore, although females are included in the figures reported by table 1 for comparison purposes, they will eventually be excluded from the forthcoming earnings decompositions because the female labor force participation rate in Saudi Arabia is remarkably low 4 . Also, due to cultural considerations, working in the private sector has for long been perceived as subordinate, to say the least, as compared with public sector jobs. Even within the public sector, many occupations are restricted to men, such that women are left with a limited set of occupational choices, such as in health and education where Saudi women and men follow the same pay scale. Hence, the existing sector earnings differential will not significantly be altered if females are excluded. Moreover, the small sample size does not allow for a separate discussion of women's labor force participation decisions and sector earnings differential. A much larger sample would be needed for that purpose to compensate for the very low labor force participation rate of Saudi women.

On another note, non-Saudis are not sampled because their earnings' determination is considerably different from that of their Saudi co-workers. Moreover, earnings of expatriates are irrelevant to the question of whether the nature of the sectoral earnings differential among Saudis contradicts active labor market nationalization policies. Non-Saudi earnings comprise normally of a relatively low basic salary, and then several standard monthly allowances, such as housing and transportation, are added. A significant portion of monthly earnings, however, is due to other lessstandard allowances that are subject to the candidate's relative bargaining power, country of origin and other subjective measures. This process leads earnings to vary considerably across employees, even working for the same

\footnotetext{
${ }^{2}$ An electronic survey has been distributed to 40 students registered in two Principles of Microeconomics sections at King Faisal University during the spring semester of 2013 via whatsapp. Those students, who are selected according to their area of residence, were asked to have their household members fill the survey, and forward it to their respective contacts with the request to do the same and further forward it to their contacts and so on. This procedure granted access to household members who otherwise would not be accessible, whether personally active on social media or not.

${ }^{3}$ Although considerably small if compared with datasets that are typically collected by specialized institutions, the number of responses is still larger than $n=385$; the minimum recommended sample size for a large population calculated at a $5 \%$ margin of error, a $95 \%$ confidence interval and a $50 \%$ response distribution.

${ }^{4}$ For a similar argument on excluding females, see Dustmann and Soest (1998).
} 
employer and at the very same operational unit, which raises serious concerns regarding the potential presence of wage discrimination that could be a relevant question for future research. The determination of earnings for Saudis on the other hand is far more standardized, with higher basic salaries and allowances that are less subjective. This leads to a fairly different earnings distribution as compared with that of non-Saudis. In addition, contracts of nonSaudis are typically short-term (mostly annual contracts) that are renewable an undisclosed number of times subject to the employer's convenience. Saudis, on the other hand, receive unlimited contracts, particularly in the public sector. Consequently, as Saudi's and non-Saudis are perceived and treated as fairly different types of labor, I restrict the discussion of the sector earnings differential to locals, especially at a time when the government is still attempting to have expatriates replaced by locals according to the goals of the national policy of Saudization.

Despite the relatively small sample size, comparing several sample means (including Saudi males and females) with available officially published equivalents from the Manpower Research Bulletin (CDSI, 2013) reveals remarkable resemblance. On the demographic aspect, according to the bulletin, the average age of a Saudi employee is 36 years 5 compared to 34 years as revealed by table 1, which describes the sample means and standard deviations. In general, $78 \%$ of Saudi workers are men, compared to $80 \%$ as reported by the sample. In the public sector, men constitute $62 \%$ of all Saudi workers according to government figures and $76 \%$ according to the sample. In the private sector on the other hand, these percentages increase to $81 \%$ and $86 \%$, respectively. Clearly, both data sources show a higher concentration of women in the public as opposed to the private sector. This is partially due to the cultural considerations that render women with fewer job opportunities, most of which are public sector jobs in health and education as mentioned earlier. Regarding workers' distribution among economic sectors, the bulletin reveals that $6 \%$ of all Saudi workers are employed in mining and quarrying, $83 \%$ in services, and 11\% in the production of final goods. The corresponding sample means are $9 \%, 77 \%$ and $15 \%$ in that order. Finally, government figures suggest that $56 \%$ of Saudi workers are employed in the public sector, compared to $44 \%$ working in private sector jobs. These percentages are remarkably close to the corresponding sample means of $55 \%$ and $45 \%$, respectively. Therefore, despite the general concern with the sampling method and sample size, I have sufficient reason to believe that this dataset is capable of producing meaningful inferences.

Table 1 presents the sample means and standard deviations for both sectors in the first column, and for the public and private sectors in the second and third columns. The last column shows the sector mean differences for each variable and the corresponding standard errors. Real hourly earnings are defined by the dollar value of total monthly earnings from employment in 2012 prices ${ }^{6}$ received by an individual, divided by the number of monthly working hours. Monthly earnings from employment include the basic salary and all cash allowances. In the case of an allowance that is received on an annual basis, monthly earnings are increased by one-twelfth of that allowance.

\begin{tabular}{lrrrr}
\hline \multicolumn{1}{c}{ Table 01: Sample means, standard deviations } & and sector mean differences & \\
\hline & Both & Public & Private & Mean \\
Variable & Sectors & Sector & Sector & Difference \\
\hline Real Hourly Earnings & 17.72 & 18.96 & 16.28 & $2.68^{* *}$ \\
& $(13.97)$ & $(15.22)$ & $(12.27)$ & $(1.61)$ \\
\hline Human Capital Characteristics & & & & \\
\hline Age & 33.83 & 35.09 & 32.39 & $2.69^{* * *}$ \\
& $(7.45)$ & $(7.57)$ & $(7.06)$ & $(0.84)$ \\
Gender (Male=1) & 0.80 & 0.76 & 0.86 & $-0.10^{* *}$ \\
& $(0.40)$ & $(0.43)$ & $(0.35)$ & $(0.04)$ \\
Years of Education & 17.12 & 17.36 & 16.83 & $0.53^{*}$ \\
& $(3.21)$ & $(3.40)$ & $(2.95)$ & $(0.38)$ \\
Actual Experience & 10.78 & 11.86 & 9.45 & $2.41^{* * *}$ \\
& $(7.86)$ & $(8.50)$ & $(6.78)$ & $(0.89)$ \\
Tenure & 8.61 & 10.23 & 6.68 & $3.55^{* * *}$ \\
Prepared for Job & $(7.34)$ & $(8.14)$ & $(5.70)$ & $(0.80)$ \\
& 0.79 & 0.86 & 0.71 & $0.15^{* * *}$ \\
& $(0.41)$ & $(0.35)$ & $(0.46)$ & $(0.05)$ \\
\hline Employer-Specific Characteristics & & & & \\
\hline Occupational Position (White Collar=1) & 0.39 & 0.32 & 0.47 & $-0.15^{* * *}$ \\
& $(0.49)$ & $(0.47)$ & $(0.50)$ & $(0.06)$ \\
\hline Employer Size & & & & \\
\hline Less than 20 (Reference Group) & 0.04 & 0.04 & 0.04 & 0.00 \\
Between 20 and 200 & $(0.19)$ & $(0.19)$ & $(0.19)$ & $(0.02)$ \\
& 0.29 & 0.38 & 0.19 & $0.18^{* * *}$ \\
& $(0.46)$ & $(0.49)$ & $(0.40)$ & $(0.05)$ \\
\hline
\end{tabular}

\footnotetext{
${ }^{5}$ The average age is calculated using the age-group midpoints reported in the research bulletin, whereas the sample mean is the simple average of the respondent's age at the time of survey. This could explain at a significant part of the difference in the two means, as opposed to attributing it to the potential sampling bias.

${ }^{6}$ Earnings are deflated by the Saudi consumer price index at the end of 2012, which was equal to 1.4.
} 


\begin{tabular}{lrrrr} 
More than 200 & 0.67 & 0.59 & 0.77 & $-0.18^{* * *}$ \\
& $(0.47)$ & $(0.49)$ & $(0.42)$ & $(0.05)$ \\
\hline Economic Sector & & & & \\
\hline Energy and Quarrying (Reference Group) & 0.09 & 0.03 & 0.16 & $-0.13^{* * *}$ \\
& $(0.28)$ & $(0.17)$ & $(0.37)$ & $(0.03)$ \\
Services & 0.77 & 0.92 & 0.59 & $0.33^{* * *}$ \\
& $(0.42)$ & $(0.28)$ & $(0.49)$ & $(0.05)$ \\
Goods & 0.15 & 0.05 & 0.26 & $-0.20^{* * *}$ \\
& $(0.35)$ & $(0.23)$ & $(0.44)$ & $(0.04)$ \\
\hline Family Variables & & & & 0.05 \\
\hline Marital Status (Married=1) & 0.72 & 0.74 & 0.69 & $(0.05)$ \\
& $(0.45)$ & $(0.44)$ & $(0.46)$ & $0.91^{* * *}$ \\
Total Number of Children & 1.98 & 2.39 & 1.48 & $(0.23)$ \\
& $(2.13)$ & $(2.33)$ & $(1.74)$ & 0.09 \\
Children Less than 6 Years & 0.96 & 1.00 & 0.91 & $(0.13)$ \\
Children Between 6 and 17 Years & $(1.14)$ & $(1.15)$ & $(1.13)$ & $0.54^{* * *}$ \\
Children Older than 17 Years & 0.78 & 1.02 & 0.49 & $(0.13)$ \\
& $(1.20)$ & $(1.33)$ & $(0.96)$ & $0.29^{* * *}$ \\
& 0.24 & 0.37 & 0.08 & $(0.09)$ \\
\hline Number of Observations & $(0.81)$ & $(1.02)$ & $(0.40)$ & 140 \\
\hline
\end{tabular}

Saudis working in public sector jobs, including both genders, enjoy a significant hourly earnings differential of USD2.68, reflecting a $16.5 \%$ public sector premium. For males only, this differential is USD2.22, representing a similar premium as a percentage, however. Whether this difference is due to public sector rents received by the bureaucrats of a minerals abundant state, or due to sector differences in workers' productivity-related characteristics is the main question to be answered by this paper.

As shown by the human capital characteristics, employees in the public sector tend to be older, more experienced and enjoy more tenure and a slightly higher endowment of education. On average, a public employee who is 35 years of age, has about 12 years of actual job market experience and 10 years of tenure. On the other hand, the average private sector employee who is 32 years of age has about 9 years of actual experience and 7 years of tenure. These numbers suggest that on average, workers in the public and private sectors have fairly similar job market associations.

Whether a particular worker actually matches his current job is determined by whether his education is directly related to his occupation, or whether he has received formal on-the-job training to carry out his tasks. It turns out that $86 \%$ of public employees match the job they are doing, whereas only $71 \%$ of the private employees do. Indeed, the largest Saudi public employers operate in the fields of education, health and energy, where the qualificationsoccupation matching is essential. Hence, assuming that all the aforementioned characteristics yield positive returns in both sectors, experience, tenure and being prepared for the job could be potential contributors to the observed sector earnings differential.

Regarding workers' distribution with respect to employer size, the data reveal that $38 \%$ of the public sector employees work for medium-sized employers, compared to $19 \%$ of workers in the private sector. Analogously, 59\% of workers in the public sector work for large employers, compared to $77 \%$ of private sector employees. Consequently, if earnings increase with the size of the employer, such a distribution would reduce the sector earnings differential. Moreover, with respect to the distribution of workers across economic sectors, the data show that $92 \%$ of public sector workers are employed in services, compared with 59\% of private sector employees. Hence, the effect of more public workers being employed in services depends on the relative returns of working in that particular sector. If the returns to employment in services are lower than the returns to employment in mining and energy (reference group), the earnings differential will decrease, and vise versa.

Finally, whereas there is no significant difference in workers' marital status, public sector employees has on average one more child who is older than six years. Marital status and number of children are important variables that potentially capture workers' sector preferences. In the Saudi cultural context, working for the government contributes positively to social status, and is associated with higher levels of job security and more generous nonmonetary benefits. Therefore, I expect that workers with children, particularly those attending primary and secondary school within the age group of six to seventeen years, prefer working in the public sector.

In this paper I employ the standard two-fold Blinder (1973) Oaxaca (1973) decomposition following the more general approach of Neumark (1988), Oaxaca and Ransom (1988) and Oaxaca and Ransom (1994), where the coefficients from a pooled regression over both the public and private sectors are used to evaluate the effect of differences in the predictors of sector earnings. This alteration is justified, particularly in the context of identifying 
public sector rents, since the original Blinder-Oaxaca procedure implies that the earnings differential is ascribed to underpayment of the subordinate group, men employed in the private sector in this case, rather than to overpayment of the dominant group. Estimating the sector earnings differential for Saudi men via ordinary least squares (OLS) gives rise to at least two concerns. First, potential selection bias originates from the nonrandom process of workers' self-selection into the public sector. Second, OLS estimates describe what happens at the mean level, and may be relatively blind to the relationships at the upper or lower tails of the earnings distribution. Therefore, earnings equations that underlie the decompositions are corrected for the potential sector selection bias, and furthermore, estimated coefficients are shown to be significantly not different from those obtained from corresponding quantile regressions.

Let the earnings equations in both the public $(\mathrm{g})$ and private $(\mathrm{p})$ sectors be given by

$$
\ln \left(E_{i}^{s}\right)=X_{i}^{s} \beta^{s}+e_{i}^{s} \text { where } s=g, p \text { and } i=1, \ldots, n^{s}
$$

$E_{i}^{s}$ Represents the real hourly earnings of individual $i$ in sector $s . X_{i}^{s}$ is a $(1 \times k)$ vector of socio-economic characteristics. This vector includes a dummy variable for the highest level of attained education with three categories; illiterates and dropouts who do not possess at least a high-school degree (reference group), individuals with at least a high-school diploma and at most a bachelor degree, and individuals who possess at least a bachelor degree. I also include in this vector the individual's actual experience in years and its square, a variable that expresses whether the individual matches the job he is doing, either by means of education or formal on-the-job training, and the individual's occupational position. Moreover, I include a dummy variable for the size of the individual's employer with three categories; employers with less than 20 workers (reference group), between 20 and 200 workers and those who employ more than 200 workers. Also, I include a dummy variable for the economic sector with three categories; mining and energy (reference group), the tangible goods sector and the services sector. $\beta^{\mathrm{s}}$ is the (k $\times 1$ ) vector of estimated coefficients and $e_{i}^{s}$ is the corresponding error term.

Note that the right-hand side of equation 1 is conditional upon the individual's sector choice. Hence, as proposed by Heckman (1979), it is necessary to introduce an equation that explains worker's selection decision:

$$
\mathrm{P}_{\mathrm{i}}^{*}=\mathrm{Z}_{\mathrm{i}} \gamma+\mathrm{u}_{\mathrm{i}} \text { where } \mathrm{i}=1, \ldots, \mathrm{N}, \quad \ldots(2)
$$

Where $\mathrm{P}_{\mathrm{i}}^{*}$ is a latent variable that reflects the individual's sector choice. This variable's observable counterpart $\mathrm{P}_{\mathrm{i}}$ is a binary variable that takes the value of $P_{i}=1$ if $P_{i}^{*}>0$ and the value of $P_{i}=0$ otherwise. $Z_{i}$ is a $(1 \times k)$ vector of characteristics that explain the individual's sector choice. Since this is a labor supply function, however, this vector includes vector $\mathrm{X}_{\mathrm{i}}^{\mathrm{S}}$ and another set of variables that would influence the individual's sector choice but not his earnings. These variables are marital status; indicating whether the individual is currently married or not (not married includes being single, widowed or divorced) and number of children in three different age groups; younger than six years, between six and seventeen, and older than seventeen years. Government jobs in Saudi Arabia are perceived to reflect a higher social status and believed to provide higher levels of job security and non-monetary benefits, such as annual leaves, health insurance and promotion prospects. Therefore, in pursuit of higher status, security and benefits, I assume that individuals are more likely to select employment in a government job if married, particularly in the presence of children who are of the age to attend primary or secondary school, where their costs start to rise. $\gamma$ is the $(\mathrm{k} \times 1)$ vector of estimated coefficients and $\mathrm{u}_{\mathrm{i}}$ is the corresponding error term. The error terms of equations 1 and 2 above are assumed to be normally distributed and correlated $\left(e_{i}, u_{i}\right) \sim N\left(0,0, \sigma_{e}^{2}, 1, \rho_{e u}\right)$, and independent of the set of explanatory variables.

First, equation 2 is estimated as a probit, whose coefficients are then used to calculate the inverse Mill's ratio $\lambda_{\mathrm{i}}\left(-\mathrm{Z}_{\mathrm{i}} \gamma\right)=\varphi\left(-\mathrm{Z}_{\mathrm{i}} \gamma\right) /\left[1-\emptyset\left(-\mathrm{Z}_{\mathrm{i}} \gamma\right)\right] . \varphi\left(-\mathrm{Z}_{\mathrm{i}} \gamma\right)$ denotes the standard normal density function and $\emptyset\left(-\mathrm{Z}_{\mathrm{i}} \gamma\right)$ denotes the standard normal cumulative distribution function. Then, the inverse Mill's ratio is included in equation 1 above as a further predictor:

$$
\ln \left(E_{i}^{s}\right)=X_{i}^{s} \beta^{s}+\beta_{\lambda}^{s} \lambda_{i}^{s}+v_{i}^{s} \text { where } s=g, p \text { and } i=1, \ldots, n^{s}
$$

where $\beta_{\lambda}^{\mathrm{s}}=\rho_{\mathrm{eu}}^{\mathrm{s}} \sigma_{\mathrm{e}}^{\mathrm{s}}$; the covariance between the errors from the probit and the earnings equations multiplied by the standard error of the earnings equation. $v_{i}^{s}$ is the standard error term of each sector's earnings equation after correcting for selection bias, such that $\mathrm{v}_{\mathrm{i}}^{\mathrm{s}} \sim \mathrm{N}\left(0, \sigma_{\mathrm{v}}^{\mathrm{s}}\right)$.

Given equation 3 above, the mean sector log earnings differential can be written as

$$
\overline{\mathrm{D}}=\left(\overline{\mathrm{X}}^{\mathrm{g}} \widehat{\beta}^{\mathrm{g}}-\overline{\mathrm{X}}^{\mathrm{p}} \widehat{\beta}^{\mathrm{p}}\right)+\left(\widehat{\beta}_{\lambda}^{\mathrm{g}} \bar{\lambda}^{\mathrm{g}}-\widehat{\beta}_{\lambda}^{\mathrm{p}} \bar{\lambda}^{\mathrm{p}}\right)
$$

Furthermore, adding and subtracting the terms $\overline{\mathrm{X}}^{\mathrm{g}} \widehat{\beta}^{*}$ and $\overline{\mathrm{X}} \mathrm{p} \widehat{\beta}^{*}$ to the first difference on the right-hand side of equation 4 and the terms $\widehat{\beta}_{\lambda}^{*} \bar{\lambda}^{\mathrm{g}}$ and $\widehat{\beta}_{\lambda}^{*} \bar{\lambda}^{\mathrm{p}}$ to the second difference, yields the two-fold Blinder-Oaxaca decomposition as expressed by equation 5 below, which takes into account the composition of the selection bias and uses a 
nondiscriminatory coefficients vector to determine the contribution of differences in the predictors to the publicprivate earnings differential:

$$
\begin{aligned}
& \overline{\mathrm{D}}=\left[\left(\overline{\mathrm{X}}^{\mathrm{g}}-\overline{\mathrm{X}}^{\mathrm{p}}\right) \hat{\beta}^{*}+\left(\bar{\lambda}^{\mathrm{g}}-\bar{\lambda}^{\mathrm{p}}\right) \hat{\beta}_{\lambda}^{*}\right]+ \\
& \underbrace{\text { Explained Differential }} \\
& {\left[\bar{X}^{\mathrm{g}}\left(\widehat{\beta}^{\mathrm{g}}-\widehat{\beta}^{*}\right)+\overline{\mathrm{X}}^{\mathrm{p}}\left(\widehat{\beta}^{*}-\widehat{\beta}^{\mathrm{p}}\right)+\bar{\lambda}^{\mathrm{g}}\left(\widehat{\beta}_{\lambda}^{\mathrm{g}}-\widehat{\beta}_{\lambda}^{*}\right)+\bar{\lambda}^{\mathrm{p}}\left(\widehat{\beta}_{\lambda}^{*}-\widehat{\beta}_{\lambda}^{\mathrm{p}}\right)\right] \text {. }} \\
& \text { Unexplained Differential }
\end{aligned}
$$

The $\widehat{\beta}^{*}$ s are the nondiscriminatory coefficients obtained from a pooled regression over both sectors. The first term of the explained differential in equation 5 is the share of the differences in the predictors, while the second term is the explained part of the potential selection bias (the mean difference in the inverse Mill's ratio). Analogously, the sum of the first two terms of the unexplained differential is the share of the differences in the returns, whereas the sum of the next two terms represents the unexplained part of the potential selection bias.

\subsection{Empirical results}

Table 2 presents the sector choice probit and the corresponding marginal effects in the first and second columns, the selectivity corrected earnings equations for each sector in the third and fourth columns, and the equivalent OLS equations in the fifth and sixth columns. The probit and marginal effects output show that whenever the individual matches his current job plays a significant role in the choice of sector. The marginal effect indicates that being educated or formally trained for the job increases the probability of working in the public sector by $25.6 \%$. This corresponds to the observation in table 1, that the percentage of employees who do match their jobs is significantly higher in the public sector. Also, the economic sector plays a significant role in the selection process, as the probability of being employed in a government job increases by $35.4 \%$ if the individual works in services. This result is rather unsurprising, given that more than three-quarters of employed Saudi men do, in fact, work in services, namely health and education. Furthermore, whereas being married does not affect the choice of sector, the pres ence of dependent children does. Marginal effects show that having one child within the age group six to seventeen years increases the probability of working for the government by $12.2 \%$. Taking into account the conservative Saudi religious and cultural environment, it is highly unlikely to have any children without currently or having been married.

Columns three and four show the selection-corrected estimation output of the male earnings equations in each of the public and private sectors. As expected, education influences real hourly earnings positively in both sectors, and the returns to education increase with the educational level attained, ceteris paribus. For instance, having at least a high school up to a bachelor degree in the private sector leads real hourly earnings to increase by about USD1.87 as compared to the reference group, whereas possessing a graduate degree will cause real hourly earnings to increase at least by around USD2.0 in both the public and private sectors. Moreover, an additional year of actual experience leads real hourly earnings to increase by about USD1.1 in both sectors, with evident diminishing returns to experience. Implementing a Chow (1960) test reveals that the estimated coefficients are statistically not different across sectors. Therefore, I expect that the unexplained component of equation 5 to be statistically insignificant accordingly. Regarding employer-specific characteristics, results show that earnings in the goods and services sector are on average less than earnings in mining and energy. For example, government employees in the services sector earn about USD1.7 per hour less, compared with their counterparts who are employed in mining and energy. This result is consistent with the general observation that Saudi workers in services such as health and education are paid less than their peers who work in the oil industry and other energy-related businesses. In fact, many young Saudis grow up with the dream of working for employers such as the public Saudi Aramco, which is a leading petroleumbased energy producer. Hence, it is of no surprise that the inverse Mill's ratio appears to be highly significant in the public sector, where the negative sign suggests that observed earnings are less than offer earnings.

The last two columns of table 2 verify the potential bias of coefficients estimated via OLS without correcting for selection. Generally, OLS overestimates the returns to most characteristics, particularly in the public sector as also observed in the case of Greece by Kanellopoulos (1997). For example, the returns to the education are overestimated by around USD1.0 per hour for each educational category, and the returns to working in the services sector are overestimated by USD1.5 per hour. Therefore, unless the bias is fixed across both sectors, the earnings differential estimated via OLS would also be potentially biased.

\begin{tabular}{ccccc}
\hline & \multicolumn{4}{c}{ Table 02: Probability of joining the public sector, and sector earnings equations } \\
\hline \multirow{2}{*}{ Variable } & Sector & Marginal & Selection Bias & OLS \\
& Probit & Effect & Corrected & OLed \\
\hline
\end{tabular}

\footnotetext{
${ }^{7}$ Real hourly earnings are measured in natural logarithms. Hence, a coefficient of 0.585 translates into $e^{0.585}=$ USD1.795.
} 


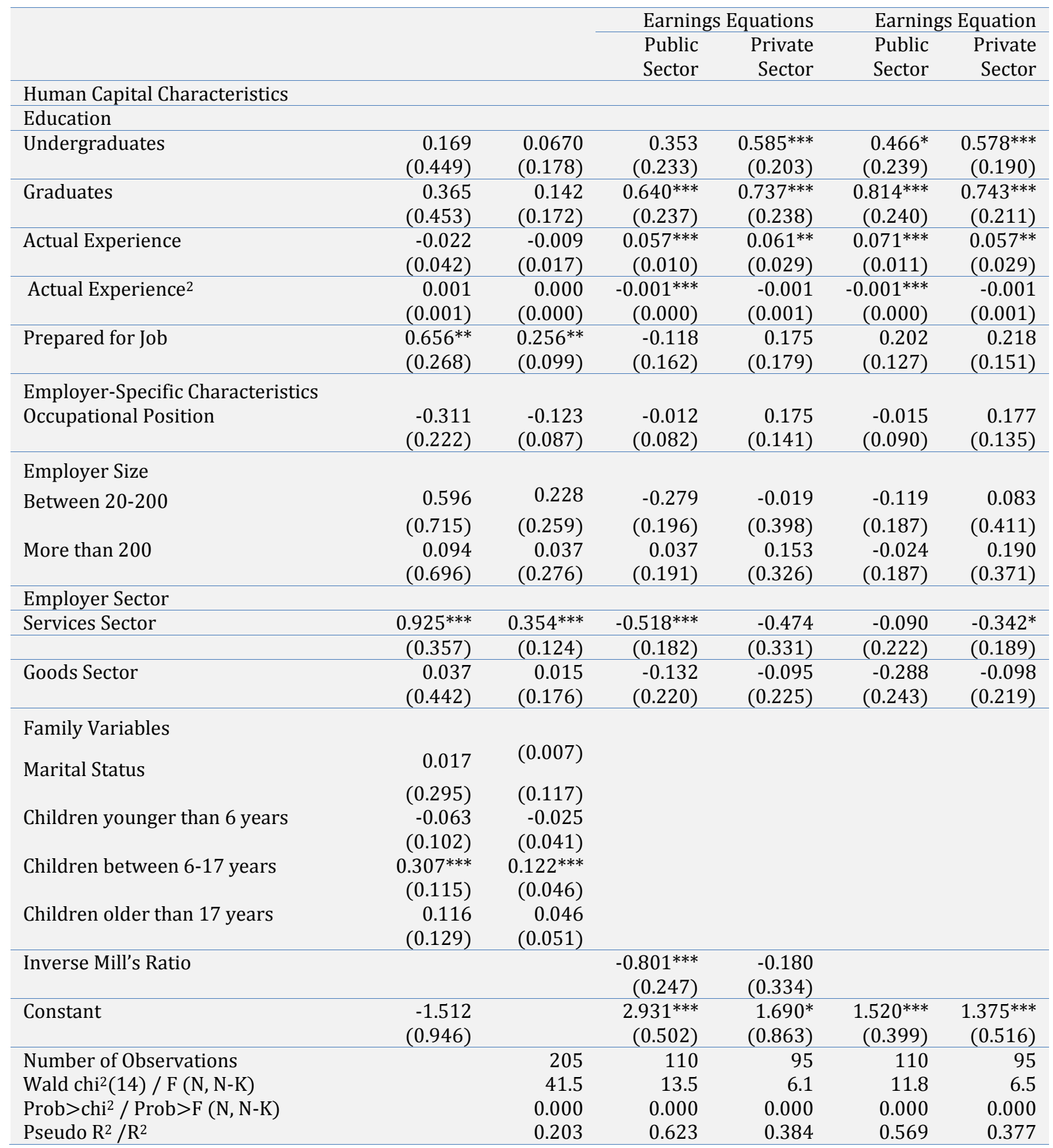

Figure 1 below shows the quantile regression coefficients of the earnings equations in both sectors, along with the selection-corrected coefficients estimated by equation 3 and their corresponding 99\% confidence intervals. Panels (A) and (B) clearly show that all quantile regression coefficients fall within the confidence intervals. Hence, there is no reason to believe that the earnings decompositions would yield different results within different percentiles of the earnings distributions. 
Figure 01.A : The selection-corrected coefficients and the coefficients from corresponding Quantile regressions within $99 \%$ confidence intervals
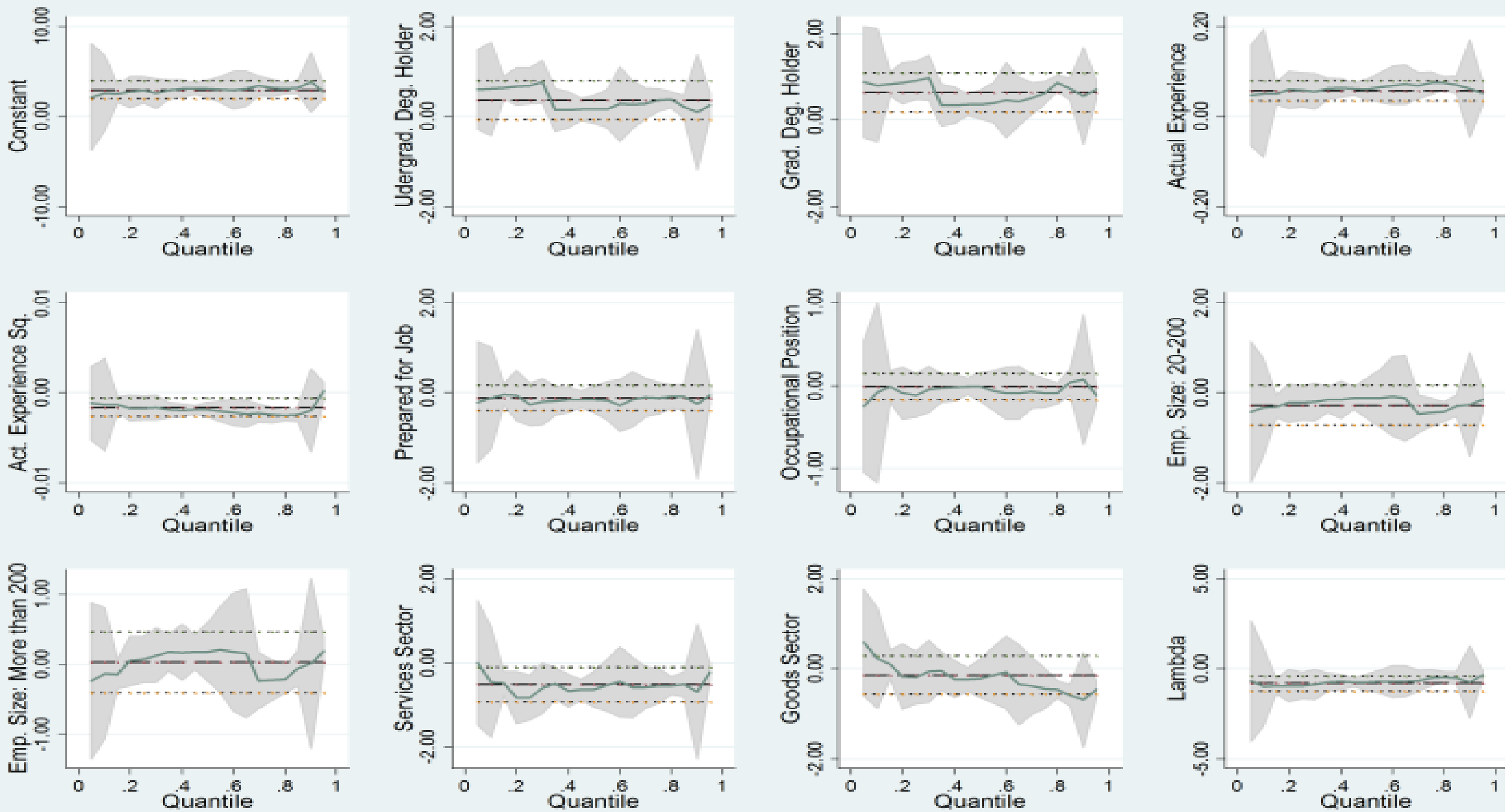
Figure 01.B : The selection-corrected coefficients and the coefficients from corresponding Quantile regressions within 99\% confidence intervals
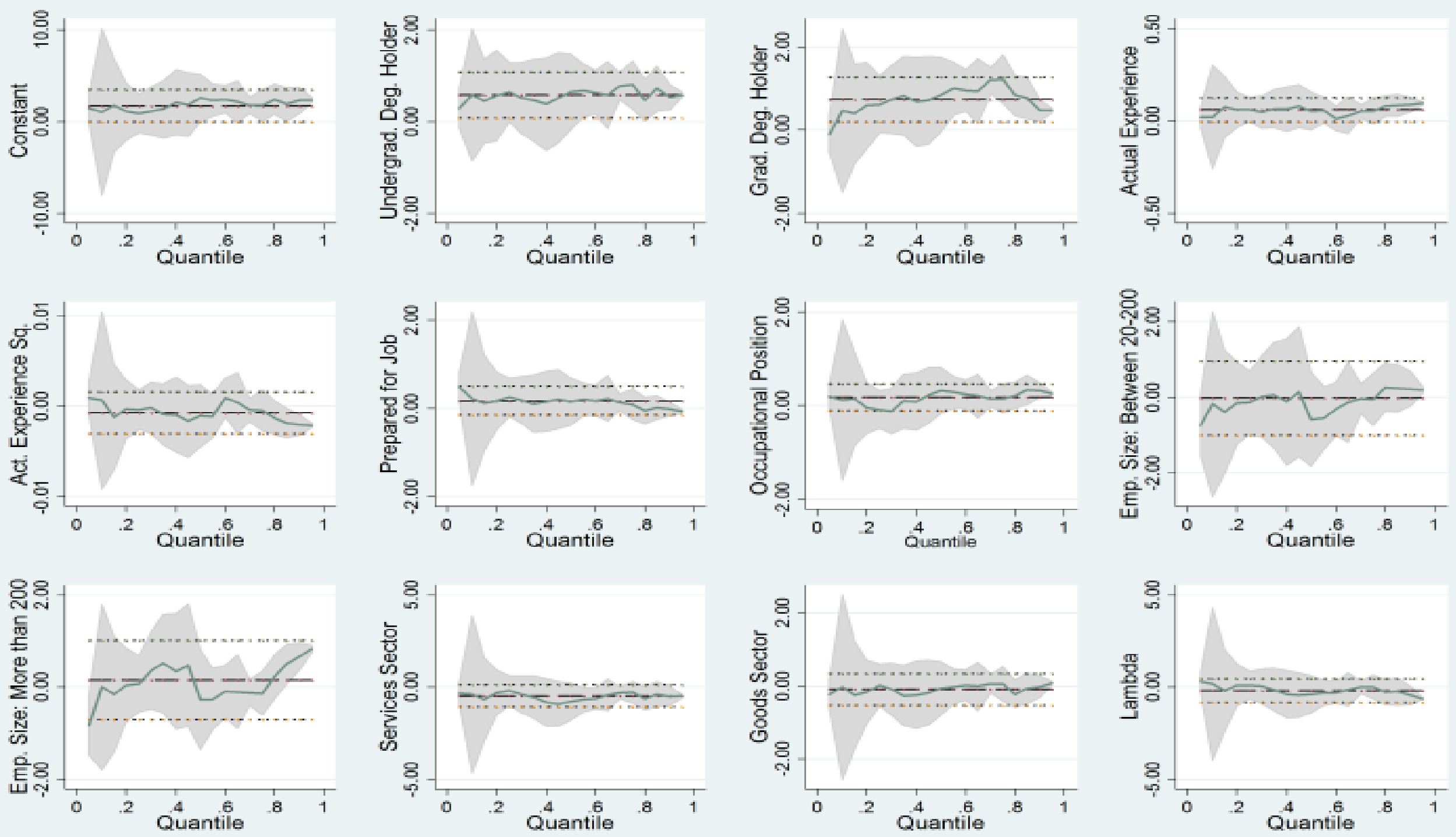
Table 3 shows the two-fold Blinder-Oaxaca decomposition at the mean level of Saudi male earnings distributions, using coefficients that are corrected for worker's sector selection decisions. The upper part of the table demonstrates how the differential decomposes, on aggregate, into an explained component (i.e. the first term of equation 5) and an unexplained component (i.e. the second term of equation 5). Clearly, the total earnings differential of USD2.22 per hour $\left(e^{2.750}-e^{2.597}\right)$ is entirely explained by the average differences in worker's characteristics between both sectors. The explained component of the earnings differential is statistically different from zero and accounts for $100 \%$ of the total gap, whereas the unexplained component is insignificant statistically, and quantitatively negligible. This result corresponds to the earlier observations, where the sector differences in the sample means were almost all statistically significant, and where none of the individual differences in the estimated sector returns was statistically different from zero.

The lower part of table 3 presents the decomposition details, showing the characteristics to which the total differential can actually be attributed. These are actual work experience, being employed in the services sector, and worker's sector selection decisions. Actual work experience is on average higher in the public sector as compared to the private sector. Since the experience has positive returns, this difference results in a statistically and quantitatively significant positive contribution to the earnings differential equal to $0.173 \log$ points $(113.1 \%$ of the total sector earnings differential). Diminishing returns to work experience, on the other hand, counterbalances the strong positive influence of the sector experience differential, reducing the sector earnings differential by 0.085 log points (negative $55.6 \%$ of the total sector earnings differential). Differences in education and preparation for the job seem irrelevant to the Saudi male earnings differential between public and private sector, contrary to the findings of Lassibille (1998), Tansel (2005), Caserol and Seshan (2006) and Okurut and Ssewanyana (2007).

Also, the economic sector of employment plays a remarkable role in determining sector earnings differentials. Results indicate that working in services narrows the earnings gap by 0.149 log points (negative $97.4 \%$ of the total sector earnings differential). The main reason for this is that the percentage of Saudi men working in public services is significantly higher compared to those working in services provided by private enterprises. And since earnings in the services sector are relatively lower compared with earnings in mining and energy as revealed by the negative coefficients in the earnings equations, the sector earnings differential would be reduced accordingly. Furthermore, the component of the earnings differential that is due to workers' sector selection is 0.167 log points $(109.2 \%$ of the total sector earnings differential).

\begin{tabular}{|c|c|c|}
\hline \multicolumn{3}{|c|}{ Table 03: The two-fold Blinder-Oaxaca decomposition } \\
\hline \multicolumn{3}{|c|}{ Overall Decomposition } \\
\hline In(Public Real Hourly Earnings) & & $\begin{array}{r}2.750^{* * *} \\
(0.052)\end{array}$ \\
\hline ln(Private Real Hourly Earnings) & & $\begin{array}{r}2.597^{* * *} \\
(0.072)\end{array}$ \\
\hline Sector Earnings Differential & & $\begin{array}{r}0.153^{*} \\
(0.088)\end{array}$ \\
\hline Explained Earnings Differential & & $\begin{array}{l}0.155^{* *} \\
(0.071)\end{array}$ \\
\hline Unexplained Earnings Differential & & $\begin{array}{r}-0.002 \\
(0.079)\end{array}$ \\
\hline \multicolumn{3}{|c|}{ Detailed Decomposition } \\
\hline Variable & $\begin{array}{r}\text { Explained } \\
\text { Differential }\end{array}$ & $\begin{array}{r}\text { Unexplained } \\
\text { Differential }\end{array}$ \\
\hline \multicolumn{3}{|l|}{ Human Capital Characteristics } \\
\hline \multicolumn{3}{|l|}{ Education } \\
\hline Undergraduates & $\begin{array}{r}0.015 \\
(0.031)\end{array}$ & $\begin{array}{r}-0.148 \\
(0.187)\end{array}$ \\
\hline Graduates & $\begin{array}{r}0.024 \\
(0.047)\end{array}$ & $\begin{array}{r}-0.030 \\
(0.097)\end{array}$ \\
\hline Actual Experience & $\begin{array}{l}0.173^{* *} \\
(0.076)\end{array}$ & $\begin{array}{r}-0.068 \\
(0.306)\end{array}$ \\
\hline Actual Experience ${ }^{2}$ & $\begin{array}{r}-0.085^{* *} \\
(0.043)\end{array}$ & $\begin{array}{r}0.004 \\
(0.142)\end{array}$ \\
\hline Prepared for Job & $\begin{array}{r}0.029 \\
(0.026)\end{array}$ & $\begin{array}{r}-0.252 \\
(0.186)\end{array}$ \\
\hline $\begin{array}{l}\text { Employer-Specific Characteristics } \\
\text { Occupational Position }\end{array}$ & $\begin{array}{r}-0.008 \\
(0.010)\end{array}$ & $\begin{array}{r}-0.081 \\
(0.066)\end{array}$ \\
\hline Employer Size & & \\
\hline Between 20-200 & $\begin{array}{r}-0.020 \\
(0.039)\end{array}$ & $\begin{array}{r}-0.088 \\
(0.103)\end{array}$ \\
\hline More than 200 & -0.020 & -0.081 \\
\hline
\end{tabular}




\begin{tabular}{lrr} 
& $(0.036)$ & $(0.259)$ \\
Employer Sector & & \\
Services Sector & $-0.149^{* *}$ & -0.039 \\
Goods Sector & $(0.064)$ & $(0.263)$ \\
& 0.028 & -0.011 \\
Inverse Mill's Ratio & $(0.034)$ & $(0.042)$ \\
\hline Constant & $0.167^{*}$ & -0.448 \\
& $(0.090)$ & $(0.316)$ \\
\hline
\end{tabular}

Finally, not only are the unexplained elements insignificant as a group, but also individually none is statistically different from zero, including the constant and the selection term. Therefore, adding up all the individually significant factors of the explained component, they account for $69.3 \%$ of the total sector earnings differential for Saudi men. In other words, actual working experience, working in the services sector and selection explain USD1.54 of the total USD2.22 sector male earnings gap.

Given the results above, the fact that locals are concentrated in public sector jobs as opposed to private jobs is not a result of higher earnings in the public sector. It is that locals with higher average human capital characteristics choose to work in public jobs that are typically associated with favorable non-monetary attributes. This in turn leads average earnings to be higher in the public sector.

An important implication of this finding is that policy measures designed to encourage private sector employment of locals should focus on reasons other than the public wage structure. Reasons that actually cause private sector jobs to be dominantly occupied by expatriates. One cause originates from the demand side. That is, private employers have strong preferences towards employing expatriates due to higher productivity levels, ease of hiring and firing, higher tolerance of job-related disamenities and higher levels of acceptance of particular occupations. In addition, expatriates tend to accept lower wages, which altogether leads cost-minimizing private employers to hire more expatriates. Given these circumstances, current policies that enforce employment quotas, force private employers to hire more of the less preferred, yet more expensive input. This ultimately increases production costs and, ceteris paribus, decreases profits. Therefore, private employers possess sufficient incentive to bypass such employment quotas. It is about time for labor market policies to tackle the issue from the correct angle. Reforms should be directed towards increasing the productivity of locals to better compete with expatriate labor, by investing in education in general, and matching the output of educational institutions with the demand for skills in the private sector in particular. Also, the government could restrict the supply of expatriate labor by tightening up entry requirements, which would in turn exert an upward pressure on their wages, making the employment of locals relatively cheaper. Such measures will eventually affect both employers hiring preferences and relative wages in favor of locals. On the other hand, it is the responsibility of the whole society to introduce some changes in the general attitude towards certain occupations with lower skill requirements that are typically performed exclusively by expatriates. Finally, in order to augment and expedite the above mentioned rather long term corrective reforms, the government could consider subsidizing private employment of locals by allocating sufficient oil revenues towards a healthier and more balanced sectoral distribution of the local labor force.

\subsection{Conclusions and policy implication}

This paper is the first to address the determination of Saudi male earnings in the public and private sectors, workers' sector choice, as well as the sector earnings differential. For this purpose, I use a newly collected dataset and implement a two-fold Blinder-Oaxaca decomposition where the coefficients from a pooled regression over both the public and private sectors are used to evaluate the effect of differences in the predictors of sector earnings.

Sector earnings equations that are corrected for workers' sector selection decisions reveal that earnings in both sectors are most significantly affected by workers' education and actual job market experience, as well as by the economic activity of the employer. Saudi men are more likely to be self-selected into the public sector, the better they match the job they ultimately are assigned to do, and the more children they have who are of the age to attend primary or secondary schools. Also, working in services contributes positively to the probability of being employed in the public sector. Results also show that coefficients estimated at different quartiles of the earnings distribution are significantly no different from those estimated at the mean level. Hence, decomposition results will not vary with respect to the position within the earnings distribution.

Moreover, this paper shows that the statistically significant sector male earnings differential of USD2.22 per hour is entirely explained by differences in workers' observable characteristics, of which actual experience, economic sector of employment, and selection account for around 70\%. 
It is of similar importance to notice what does not explain the sector earnings differential, namely returns. This indicates that identical Saudis do not receive a public sector rent, which is consistent with the objectives of current labor market policies that attempt to increase private sector employment. Yet, the absence of higher private returns that would compensate for the favorable social status and non-monetary public employment conditions, such as higher job security, lower work stress and lower effective working hours, makes it extremely difficult for active Saudi labor market policies to achieve their objectives. As a result, the status quo is that the public sector is the main employer of locals, whereas the private sector is dominated by an expatriate labor force. If the government of Saudi Arabia wishes to increase private sector employment of locals, current policies should be altered to change private employers' preferences in favor of locals by investing in their overall productivity, re-designing educational outcomes to better match the private sector's skill requirements and create a culture of acceptance of certain low skill occupations, to name a few. Also, the government could choose to restrict the supply of expatriate labor, customize work permit requirements to strictly accommodate local skill shortages and even subsidize private employment of locals to alter relative wages in favor of Saudis.

\section{References}

Akhmedjonov, Alisher, \& Izgi, Berna, 2012. Does it pay to work in the public sector in Turkey? Applied Economics Letters, Taylor and Francis Journals, 19(10): 909-913.

Annual Statistical Bulletin 2013. Organization of the Petroleum Exporting Countries, ISSN 0475-0608.

Aslam, Monazza \& Kingdon, Geeta, 2009. Public-private sector segmentation in the Pakistani labour market. Journal of Asian Economics, Elsevier, 20(1): 34-49.

Bedi, Arjun, 1998. Sector choice, multiple job holding and wage differentials: Evidence from Poland. Journal of Development Studies, Taylor \& Francis Journals, 35(1): 162-179.

Birch, Elisa, 2006. The public-private sector earnings gap; in Australia: A quantile regression approach. Australian Journal of Labour Economics, Bankwest Curtin Economics Centre (BCEC), Curtin Business School, vol. 9(2): 99123.

Blinder, Alan S., 1973. Wage discrimination: Reduced form and structural estimates. Journal of Human Resources, University of Wisconsin Press, 8(4): 436-455.

Central Department of Statistics and Information, 2013. Manpower Research Bulletin, Riyad.

Chatterji, Monojit, Mumford, Karen, \& Smith, Peter, 2011. The public-private sector gender wage differential in Britain: Evidence from matched employee-workplace data. Applied Economics, Taylor and Francis Journals, 43(26): 3819-3833.

Chow, Gregory C., 1960. Tests of equality between sets of coefficients in two linear regressions. Econometrica, 28(3): 591-605.

Christofides, Louis N., \& Pashardes, Panos, 2002. Self/paid-employment, public/private sector selection, and wage differentials. Labour Economics, Elsevier, 9(6):737-762.

Démurger, Sylvie, Li, Shi, \& Yang, Juan, 2012. Earnings differentials between the public and private sectors in China: Exploring changes for urban local residents in the 2000s. China Economic Review, Elsevier, 23(1): 138-153.

Dustmann, Christian, \& van Soest, Arthur, 1998. Public and private sector wages of male workers in Germany. European Economic Review, Elsevier, 42(8):1417-1441.

Giordano, Raffaela, 2010. The public sector pay gap in Italy. Politica economica, Società editrice il Mulino, 2:293.

Heitmueller, Axel, 2006. Public-private sector pay differentials in a devolved Scotland. Journal of Applied Economics, Universidad del CEMA, 0: 295-323.

Hendrik, Jürges, 2002. The distribution of the German public-private wage gap. Labour, CEIS, 16(2): $347-381$.

Hyder, Asma \& Reilly, Barry, 2005. The public and private sector pay gap in Pakistan: A quantile regression analysis. The Pakistan Development Review, Pakistan Institute of Development Economics, 44(3): 271-306.

Imbert, Clément, 2013. Decomposing the labor market earnings inequality: The public and private sectors in Vietnam, 1993-2006. World Bank Economic Review, World Bank Group, 27(1):55-79.

International Monetary Fund, 2013. IMF country report No. 13/230: Saudi Arabia: Selected issues. Retrieved from www.imf.org/external/pubs/ft/scr/2013/cr13230.pdf.

Kanellopoulos, Costas, 1997. Public-private wage differentials in Greece. Applied Economics, Taylor and Francis Journals, 29(8): 1023-1032.

Lassibille, Gerard, 1998. Wage gaps between the public and private sectors in Spain. Economics of Education Review, Elsevier, 17(1): 83-92.

Lausev, Jelena, 2014. What has 20 years of public-private pay gap literature told us? Eastern European Transitioning vs. Developed Economies. Journal of Economic Surveys, 23(3): 516-550.

Lucifora, Claudio \& Meurs, Dominique, 2006. The public sector pay gap in France, Great Britain and Italy. Review of Income and Wealth, International Association for Research in Income and Wealth, 52(1): 43-59.

Meurs, Dominique \& Edon, Cyriaque, 2007. France: A limited effect of regions on public wage differentials? Manchester School, University of Manchester, 75(4): 479-500. 
Mueller, Richard E., 1998. Public-private sector wage differentials in Canada: evidence from quantile regressions. Economics Letters, Elsevier, 60(2):229-235.

Mumford, Karen, \& Chatterji, Monojit, 2012. Flying high and laying low in the public and private sectors: A comparison of pay differentials for male, full-time employees. Australian Journal of Labour Economics, Bankwest Curtin Economics Centre, Curtin Business School, 15(3): 235-259.

Neumark, David, 1988. Employers' discriminatory behavior and the estimation of wage discrimination. Journal of Human Resources, 23: 279-295.

Oaxaca, Ronald, 1973. Male-female wage differentials in urban labor markets. International Economic Review, Department of Economics, University of Pennsylvania and Osaka University Institute of Social and Economic Research Association, 14(3): 693-709.

Oaxaca, Ronald L., \& Ransom Michael R., 1988. Searching for the effect of unionism on the wages of union and nonunion workers. Journal of Labor Research, 9: 139-148.

Oaxaca, Ronald L., \& Ransom, Michael R., 1994. On discrimination and the decomposition of wage differentials. Journal of Econometrics, Elsevier, 61(1): 5-21.

Okurut, Francis N., \& Ssewanyana, Sarah, 2007. Determinants of wage earnings in Uganda. The IUP Journal of Agricultural Economics, IUP Publications, 0(2): 60-79.

Paloma, Anós, Casero1, \& Ganesh, Seshan, 2006. Public-private sector wage differentials and returns to education in Djibouti. World Bank Policy Research Working Paper 3923.

Panizza, Ugo, \& Qiang, Christine Zhen-Wei, 2005. Public-private wage differential and gender gap in Latin America: Spoiled bureaucrats and exploited women? The Journal of Socio-Economics, Elsevier, 34(6): 810-833.

Papapetrou, Evangelia, 2006. The unequal distribution of the public-private sector wage gap in Greece: Evidence from quantile regression. Applied Economics Letters, Taylor and Francis Journals, 13(4): 205-210.

Ramady, Mohamed, 2013. Gulf unemployment and government policies: Prospects for the Saudi labour quota or Nitaqat system. International Journal of Economics and Business Research, Inderscience Enterprises Ltd, $5(4): 476-498$.

Rosholm, Michael, \& Nielsen, Helena S. 2001. The public-private sector wage gap in Zambia in the 1990s: A quantile regression approach. Empirical Economics, Springer, 26(1): 169-182.

Siminski, Peter, 2013. Are low-skill public sector workers really overpaid? A quasi-differenced panel data analysis. Applied Economics, Taylor and Francis Journals, 45(14):1915-1929.

Tansel, Avsit, 2005. Public-private employment choice, wage differentials, and gender in Turkey. Economic Development and Cultural Change, University of Chicago Press, 53(2): 453-77. 